\title{
Performance Analysis of LAN and VLAN Using Soft Computing Techniques
}

\author{
Abdullahi Mohamed Haji Nur \\ ETE Department, International Islamic University Chittagong, Bangladesh
}

\begin{abstract}
The aim of this paper is to evaluate the performance of LAN and VLAN networks in different scenarios, measuring performance metrics like traffic sent, traffic received, delay and collision count in the Ethernet environment. The simulation was carried out using OPNET IT GURU ACADEMIC EDITION 9.1. To observe the performance of LAN and VLAN networks three different scenarios were presented. In the first scenario, the network consists of one hub and 16 workstations; the second scenario was connected with two hubs and a switch while the third scenario VLAN is explained and detailed, the simulation results displayed that more traffic exists in the network without VLANs, since any communication between departments is allowed, when using VLANs; it is no more possible to send traffic or access the network resources of other departments, VLANs improve the bandwidth utilization, security and the administration by supporting a virtual organization.
\end{abstract}

\section{Introduction}

A Local Area Network (LAN) was originally defined as a network of computers located within the same area. Today, Local Area Networks are defined as a single broadcast domain, This means that if a user broadcasts information on his/her LAN, the broadcast will be received by every other user on the LAN, broadcasts are prevented from leaving a LAN by using a router. The disadvantage of this method is routers usually take more time to process incoming data compared to a bridge or a switch. More importantly, the formation of broadcast domains depends on the physical connection of the devices in the network. [1][2][3]

Virtual Local Area Networks (VLAN's) were developed as an alternative solution to using routers to contain broadcast traffic. Virtual Local Area Network or VLAN is a group of logically networked devices on one or more LANs that are configured in order for them to communicate, as if they were attached to the same wire, when in fact they are located on a number of different LAN segments. With VLAN's it is easier to place members of a workgroup together. Without VLAN's, the only way this would be possible is to physically move all the members of the workgroup closer together. [4][5][6] The basic reason for splitting a network into VLANs is to reduce congestion on a large LAN. To observe the performance of LAN and VLAN networks three different scenarios were presented.

The performance metrics like traffic sent, traffic received, delay and collision count are measured and analyzed. [7] The simulation was carried out using OPNET IT GURU ACADEMIC EDITION 9.1. OPNET provides a comprehensive development environment for specification, simulation and performance analysis of communication networks. The simulation method is chosen because it can help us design the network structure, provide information about the traffic structure and save us from the cost of buying equipments and building the entire physical network structure.

\section{A. Simulation of switched LAN}

\section{Simulation}

This Scenario is designed to demonstrate the implementation of switched local area network. In this Scenario two different switching devices were used, hubs and switches. A hub forwards the packet that arrives on any of its inputs on all the outputs regardless of the destination of the packet. On the other hand, a switch forwards incoming packets to one or more outputs depending on the destination(s) of the packets. At the end we will observe how the throughput and collision of packets in a switched network are affected by the configuration of the network and the types of switching devices that are used. Different network devices ware used for connecting all the nodes together as shown in fig 4.1 and fig 4.2 


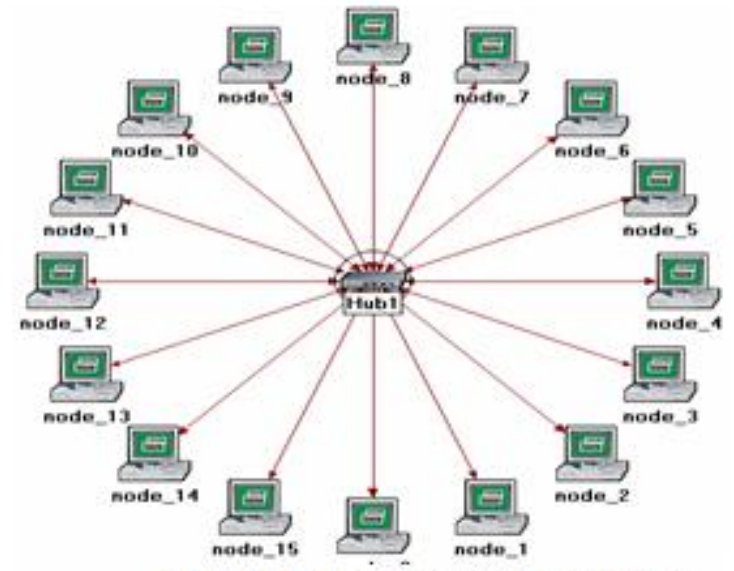

Figure 1. Office Network using only one Hub

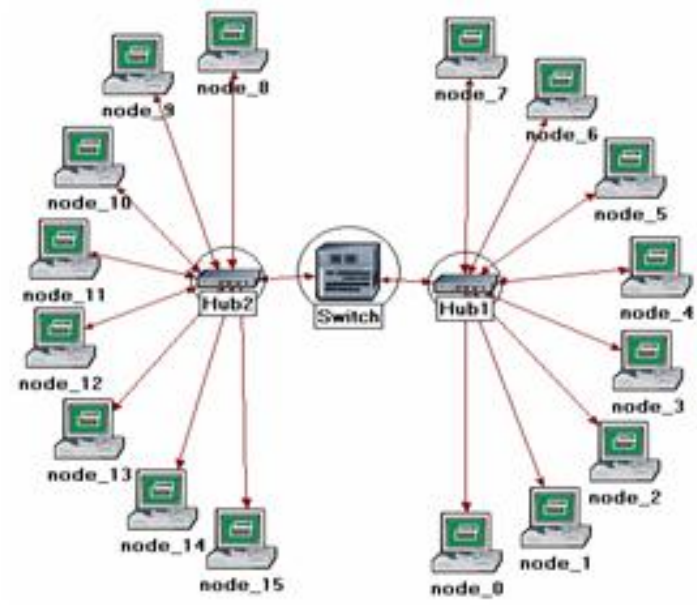

Figure 2. Office Network using two Hubs and one Switch

Figure 1 shows the first network scenario connecting all the 16 workstation together using a single hub. Figure 2 shows the second network scenario where all the 16 workstations or nodes are connected together using two hubs and one switch. Relevant performance statistics will be collected at both scenarios.

\section{B. Simulation of Virtual Local Area Network}

In this section, the Virtual LAN scenario is explained and detailed. Two scenarios were constructed to compare the behavior of a network with VLAN and another one without VLAN as shown in figure 3 and 4. This scenario is considered to be set up in an office environment with three logic groups of users which are spread around two buildings, Administration, Faculty, and Student Departments. These departments are logically separated by using a different VLAN for each of them for security purpose, and to reduce the traffic request to the servers. Table I shows how the nodes and servers are distributed and grouped into three different departments.

Table 1: Distributing Stations into departments

\begin{tabular}{|l|l|l|l|l|}
\hline Department & Server & Stations & $\begin{array}{l}\text { VLAN } \\
\text { Name }\end{array}$ & $\begin{array}{l}\text { VLAN } \\
\text { ID }\end{array}$ \\
\hline $\begin{array}{l}\text { Administration } \\
\text { Department }\end{array}$ & $\begin{array}{l}\text { Admin } \\
\text { Server }\end{array}$ & $\begin{array}{c}\text { Admin1 }- \\
\text { Admin10 }\end{array}$ & VLAN10 & 10 \\
\hline $\begin{array}{l}\text { Faculty } \\
\text { Department }\end{array}$ & $\begin{array}{l}\text { Faculty } \\
\text { Server }\end{array}$ & $\begin{array}{c}\text { faculty1- } \\
\text { faculty10 }\end{array}$ & VLAN20 & 20 \\
\hline $\begin{array}{l}\text { Student } \\
\text { Department }\end{array}$ & $\begin{array}{l}\text { Student } \\
\text { Server }\end{array}$ & $\begin{array}{l}\text { Student1- } \\
\text { Student10 }\end{array}$ & VLAN30 & 30 \\
\hline
\end{tabular}

\section{1) Switched Office Network without VLANs}

Fig. 3 represents Switched Office Network without VLANs. In this scenario there is no separation between the users, therefore every connection is permitted and it is possible for any user to have access to the Management confidential servers, all the nodes are in a single network, and they can communicate and share 
resources without restrictions, The Students can Access Administration Server, so the administration server become loaded, and finally get congested due to the high traffic requests

\section{2) Switched Office Network with VLANs}

Fig. 4 represents Switched Office Network with VLANs. It is a Network composed of three departments. These departments are logically separated by using a different VLAN for each of them. The blue arrows indicate the administration network workstations and server, the green arrows represent the faculty network workstations and server, and the red arrows are student network workstations and servers.

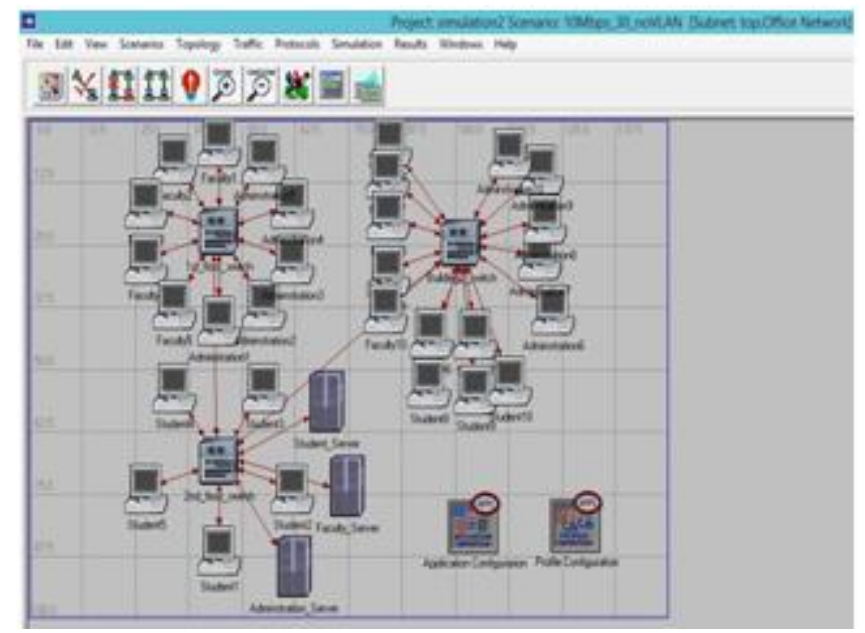

Figure 3. Switched Office Network without VLANs

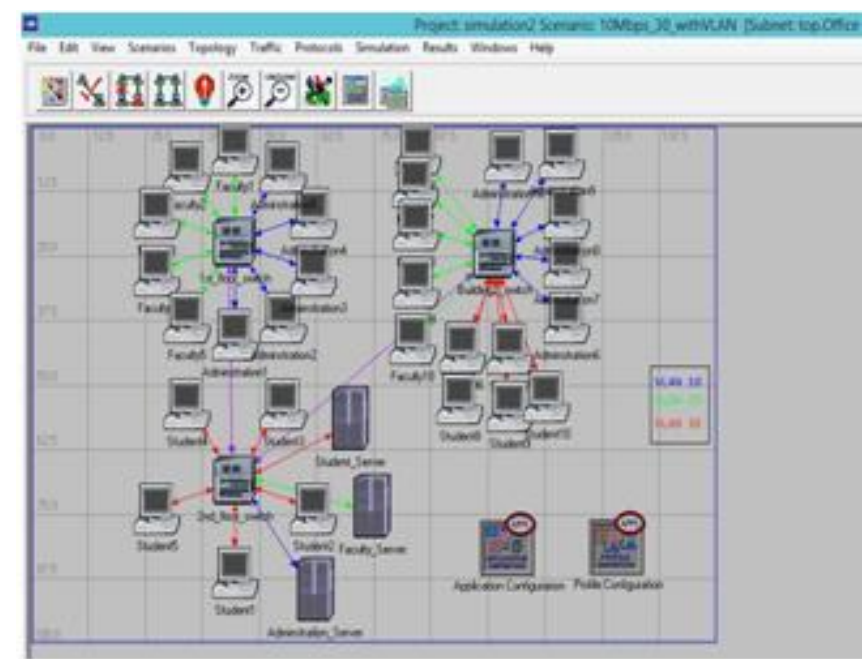

Figure 4. Switched Office Network with Three VLANs

\section{Result Analysis}

Different simulations have been executed using OPNET software for every network devices using different scenarios. The performance parameters considered in this work are Delay, Traffic Sink, Traffic Sources, and Collision. [8]

\section{A. Observations from Switched Local Area Network using Hub and Switch Traffic Sent}

It is the traffic sent by the traffic sources across all nodes measured in packets per second, as it is seen in fig. 5 the traffic sent in both scenarios is almost identical; the simulation was able to establish that packet size has a very minor effect on the network in terms of traffic sent. 


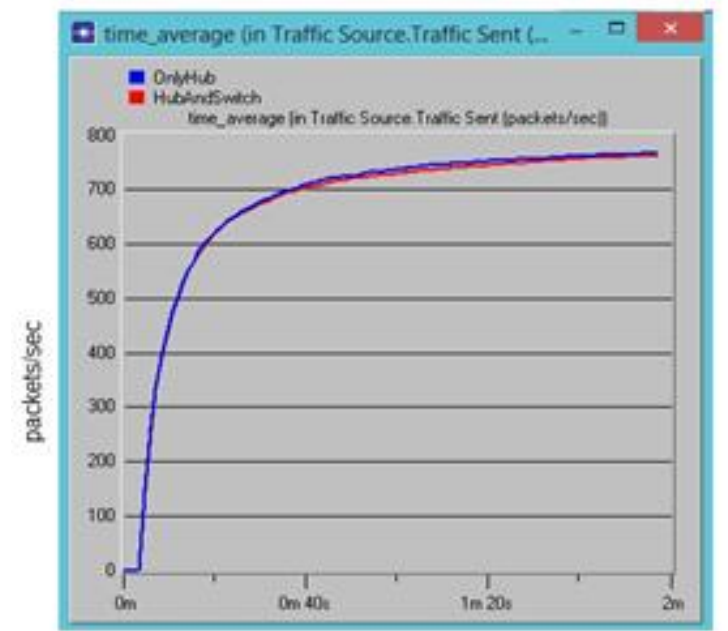

Figure 5. Traffic sent Packets/second in OnlyHub scenario

\section{Traffic Received}

The graph shown in fig. 6 is the Traffic Received (in packets/sec) by the traffic sinks across all nodes. The traffic received with the second scenario, HubAndSwitch, is higher than that of the OnlyHub scenario.

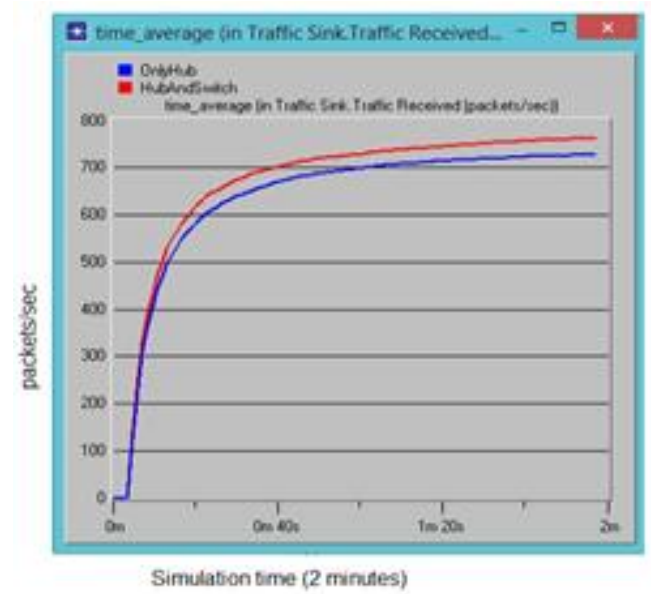

Figure 6. Traffic received (Packets/second) in HubAndSwitch scenario

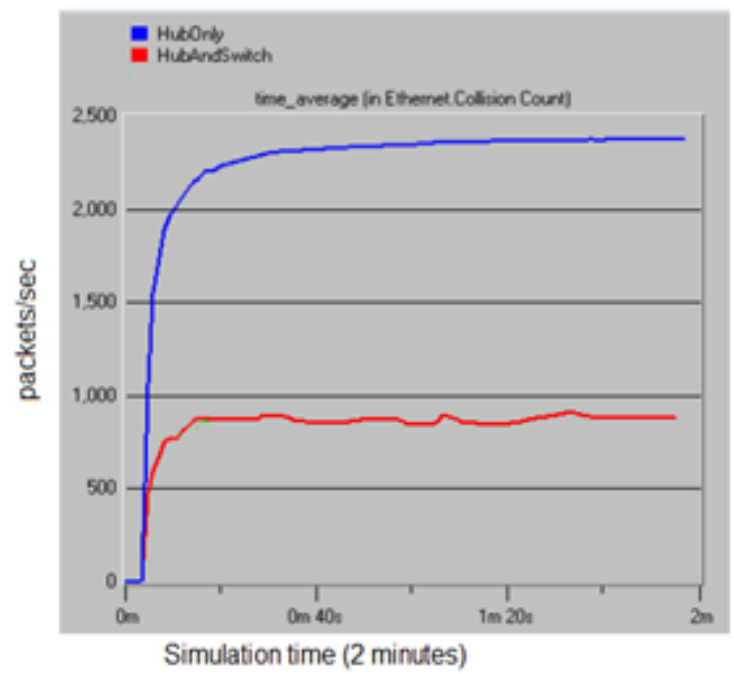

Figure 7. Average Collision count 


\section{Collision Count}

Is the total number of collisions encountered by the hub during packet transmissions, as we can see from fig. 7 the use of a switch makes it possible to reduce collisions on the network, In Ethernet, the collision is increased as the network is loaded, and this causes retransmissions and increases in load that produce even more collisions.

\section{Average Delay Analysis}

The delay shows the end to end delay of all frames received by all nodes or workstations. From fig. 8 the graph shows the average delay, we observed that the delay is high and it is not stable in case of HubOnly scenario and it is small and almost stable in case of HubAnd Switch scenario.

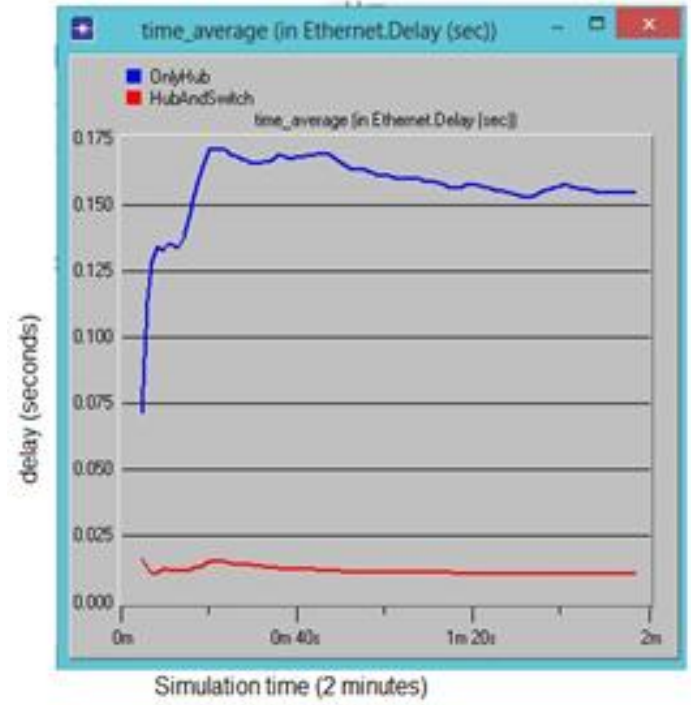

Figure 8. Average Delay

Table 2: Performance parameters

\begin{tabular}{|l|l|l|l|l|}
\hline Scenario & $\begin{array}{l}\text { Traffic } \\
\text { Sent } \\
\text { (packets/sec) }\end{array}$ & $\begin{array}{l}\text { Traffic } \\
\text { Received } \\
\text { (packets/sec) }\end{array}$ & $\begin{array}{l}\text { Collision } \\
\text { Count } \\
\text { packets }\end{array}$ & $\begin{array}{l}\text { Average } \\
\text { Delay } \\
(\text { sec) }\end{array}$ \\
\hline Only Hub & 755 & 720 & 2400 & 0.175 \\
\hline $\begin{array}{l}\text { Hub And } \\
\text { Switch }\end{array}$ & 753 & 755 & 900 & 0.0125 \\
\hline
\end{tabular}

From Table II, we can observe that the traffic Sent (load) parameters have been almost the same in both the cases. We have found that there is a slight improvement in the network performance (Traffic Received characteristics) in case of HubAndSwitch scenario.

The data shown in fig. 7 demonstrates that the network performance improves in LANs, in which LAN switches are installed, because the LAN switch creates isolated collision domains. By distributing users over several collision domains, collisions are avoided and performance improves, similarly the data shown in the Figure 4.8 demonstrates that the delay in the case with the HubAndSwitch is significantly less compared to the network configurations with the case of OnlyHub. [8]

\section{B. Observations from scenario of office network with noVLAN and withVLAN}

As show in fig. 9, 10 and 11, The Blue Graph is the No VLANs Scenario, and the Red Graph is the network with the VLAN Scenario, the traffic received in the no VLANs scenario is higher as expected because the first scenario is a single broadcast domain. If we consider figure 4.9, in the no VLANs Scenario a total of twenty workstations are transmitting database access heavy traffic request to the administration server from administration and student workstations. While the network with VLAN scenario only 10 administration workstations are sending database access heavy traffic request to the administration server, under this network design students are prevented to access the administration server, and the total network is segregated into three logical networks, and this is one of the benefits of using VLAN. 


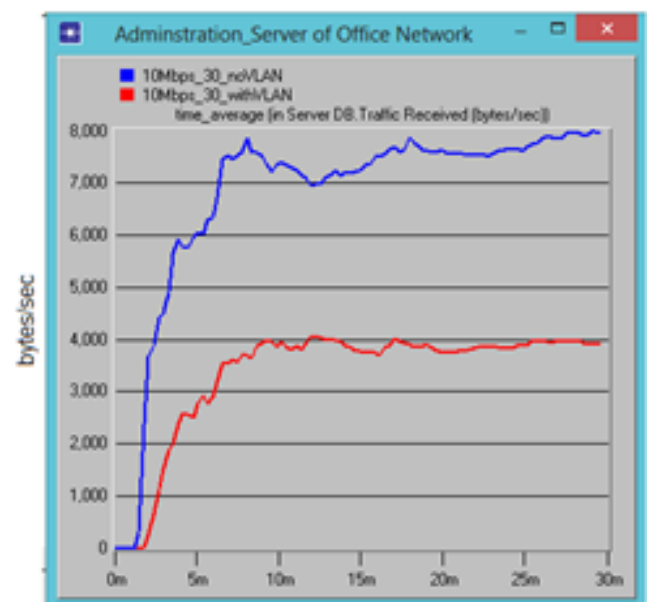

Figure 9. Traffic Request Received by the Administration Server (bytes/sec)

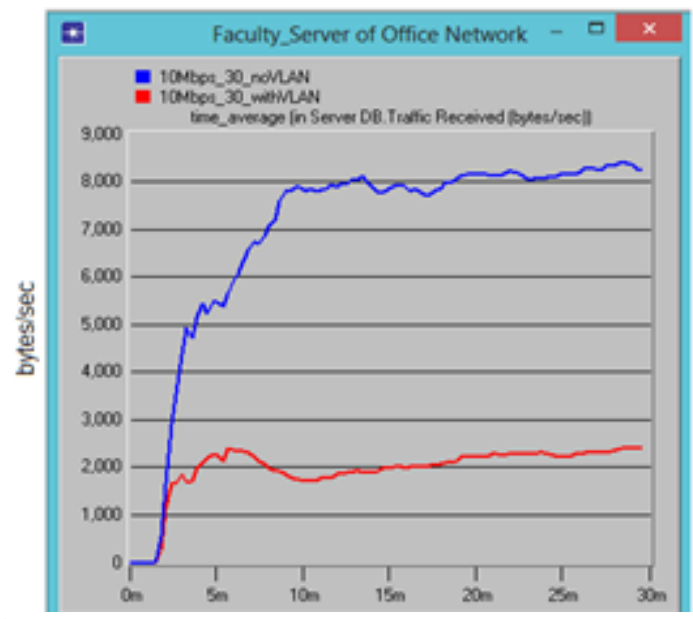

Figure 10. Traffic Request Received by the faculty Serve (bytes/sec)

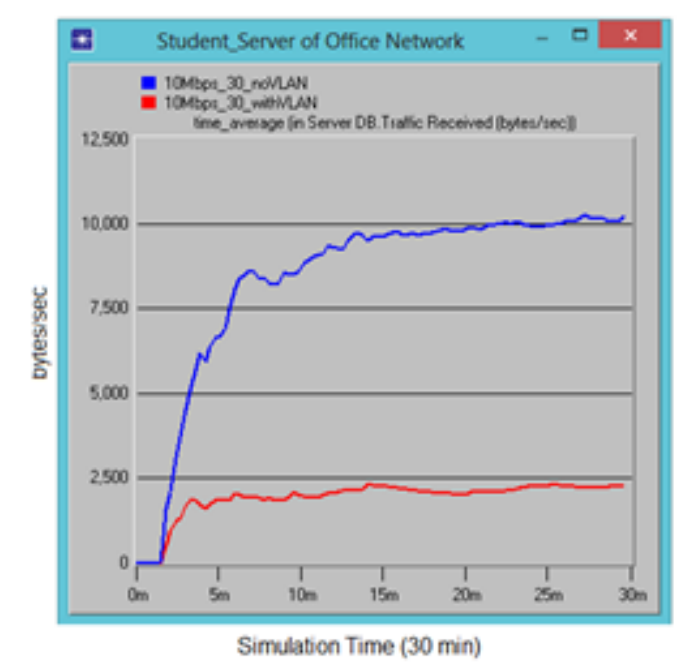

Figure 11. Traffic Request Received by the Students Server (bytes/sec)

Table 3: Traffic Follow Control

\begin{tabular}{|l|l|l|l|}
\hline Scenario & $\begin{array}{l}\text { Traffic Request } \\
\text { Received by } \\
\text { Admin Server } \\
\text { (bytes/sec) }\end{array}$ & $\begin{array}{l}\text { Traffic Request } \\
\text { Received by } \\
\text { faculty Server } \\
\text { (bytes/sec) }\end{array}$ & $\begin{array}{l}\text { Traffic Request } \\
\text { Received by } \\
\text { Students Server } \\
\text { (bytes/sec) }\end{array}$ \\
\hline $\begin{array}{l}\text { 10Mbps_30 } \\
\text { NoVLAN }\end{array}$ & 8000 & 8000 & 10000 \\
\hline 10Mbps_30WithVLAN & 4000 & 2000 & 2500 \\
\hline
\end{tabular}


The results shown in table III, indicates that VLANs are used not only for security policy, but also for traffic reduction purposes, therefore VLAN controls the traffic by reduces unnecessary traffic flow on the network and boosts performance.

\section{Conclusion}

In this study different network deployments have been considered using OPNET. In the first two LAN network deployments the packets received, packets sent, delay and collisions have been inspected. We have compared the performance and effect of the two networks in case of sending and receiving frames. Delay, Traffic Sink, Traffic Sources, Collision and Frame Size are the performance parameters. The compared simulation results show a good approximation of data traffic analyzed in the Ethernet environment and the research demonstrated that the lower the packet size better some of Ethernet network performance metric like Average utilization, collision count and delay but in some cases the packet size has no significant impact on the network performance. The simulation results shows that the network performance improves in LANs, in which switches, are installed, because the LAN switch creates isolated collision domains. By distributing users over several collision domains, collisions are avoided and performance improves

More traffic exists in the network without VLANs, since any communication between departments is allowed, when using VLANs; it is no more possible to send traffic or access some resources without authentication, it improves the bandwidth utilization, security and the administration by supporting a virtual organization.

\section{References}

[1] Sincoskie, WD "Broadband packet switching: a personal perspective." IEEE Commun. Mag. Volume 40, Issue 7, pp. 54-66, Jul. 2002.

[2] William Stallings, Data and Computer Communications, Prentice Hall, 8th Edition, 2006.

[3] Velaga Pavani, Immadisetty L V Chandrika, A.Rama Krishna "Local Area Network (LAN) Technologies" International Journal of Innovative Technology and Exploring Engineering (IJITEE) Volume 1, Issue 6, November 2012.

[4] Todd Lammle, Cisco Certified Network Associate Study Guide, Sybex, 6th Edition, 2007.

[5] Gyan Prakash Pal, Sadhana Pal "Virtual Local Area Network" International Journal of Scientific Research Engineering \& Technology (IJSRET), Volume 1, Issue 10 pp 006-010 January 2013.

[6] Behrouz A Forouzan, Data Communications \& Networking, Tata McGraw-Hill, 4th Edition, 2006

[7] D. Huckaby, "VLAN Hopping" in CCNP Switch 642-813: Official Certification Guide, Indianapolis: Cisco Press, 2011, pp. 404406.

[8] Ikram Ud Din,Saeed Mahfooz, Muhammad Adnan, "Performance Evaluation of Different Ethernet LANs Connected by Switches and Hubs, European Journal of Scientific Research, ISSN 1450-216X Vol.37 No.3 (2009), pp.461-470 